\title{
Finite element prediction of curing micro-residual stress distribution in polymeric composites considering hybrid interphase region
}

\author{
V. Teimouri and M. Safarabadi*
}

School of Mechanical Engineering, College of Engineering, University of Tehran, Tehran 11365-4563, Iran

\begin{tabular}{l}
\hline A R T I C L EI N F O \\
\hline Article history: \\
Received 26 August, 2017 \\
Accepted 20 November 2017 \\
Available online \\
20 November 2017 \\
\hline Keywords: \\
Finite element simulation \\
UMAT code \\
Interphase \\
Variable properties \\
Residual micromechanical stress
\end{tabular}

\section{A B S T R A C T}

\begin{abstract}
The interphase is a region between fibers and a matrix, which has different properties from the matrix and the fibers, but is dependent on them. Considering the interphase region has a significant effect on the accuracy of obtained residual stresses. So far, in order to obtain the micromechanical residual stresses, the interphase properties are considered as an average. In this paper, the properties of the interphase are assumed variable by using a suitable UMAT code in the ABAQUS software. The equations of previous studies that have acquired interphase properties to be variable are used to write the UMAT code. A representative volume element (RVE) in polymer composites is modeled in three phases in the ABAQUS software and the interphase properties are considered as FGM by using the UMAT code. Temperature variation during curing to environment temperature is the only loading factor in the RVE. The matrix, fiber and interphase stresses are obtained in the ABAQUS software. The achieved stresses were compared with the results of previous studies that considered interphase properties as average. Finite element and energy methods were used in previous papers but in the present study just the finite element method with variable interphase properties was use. In addition, residual stress diagrams with the variable interphase properties are plotted to study the effect of the thermal expansion coefficient. The results of this study are similar to those in previous ones, and the curves are improved.
\end{abstract}

C 2018 by the authors; licensee Growing Science, Canada.

\section{Introduction}

Residual stress is the stress that exists in the body, without the body being under external load or temperature gradients. In composite materials, after the curing process, their temperature decreases from the curing temperature to the environment temperature. Because of the incompatibility between the fibers and matrix thermal expansion coefficients, residual stresses will form (Ghasemi, 2007). Residual stresses have a major effect on the properties of composites. These stresses cause the forming

\footnotetext{
* Corresponding author

E-mail addresses: msafarabadi@ut.ac.ir (M. Safarabadi) 
of cracks in the matrix, the layering of the structure, breaking of the fibers and the fluctuation of the asymmetric multi-layers and have a significant effect on reducing the final stability of the structure. There are different numerical methods such as finite element, finite difference, boundary element and finite volume to solve engineering problems. Considering previous research, the finite element method is the most widely used method for determining residual stresses in multi-layer composites. Chen et al. (2001) investigated the non-linear viscoelasticity of the matrix in the formation of residual stresses in a multi-layer composite [0/90] by using a finite element model at a micro scale. The results of the finite element analysis showed that the higher the cooling rate, the taller the layers in residual stress will be. Also the effect of the free edge surface on the formation of residual stresses was investigated in this analysis. Tay and shen (2002) used a cracked finite element model to investigate the effect of residual stresses in layering and buckling of the layers. According to their research, the residual stress has a significant effect on the initiation of the buckling of the layered sub layer, but does not have any effect on the rate of local strain energy release during post-buckling. Karami and Garnich (2003) considered the fibers wavy form in their finite element model. Considering this issue, the thermal expansion coefficient changes as the fiber is assumed to be direct, but the amount of residual stress does not change.

Zhang et al. (2003) developed a finite element model similar to the Chen model to investigate the residual stresses during and after high-temperature curing. Based on their results, after the cooking process, the residual stresses decreases over time, and after about 34 hours, a small amount is reached. Aghdam and Khojeh (2003) studied the role of residual stresses in the stress-strain curve of a unidirectional composite under tensile longitudinal loads by considering a square-shaped element, and compared the results of the finite element solution with experimental results. Hobbiebrunken et al. (2005) performed a nonlinear finite element analysis, considering a RVE. Based on their results, a high residual shear stress during curing, causes local yield in the matrix which causes a new distribution of stress and thus lower residual stresses compared to a linear elastic matrix. The results show local yield of the matrix leads to lower stress concentration. Using a viscoelastic model in the micro scale, Zhao et al. (2006) assessed residual stresses in a glass-epoxy composite. Due to the viscoelastic behavior of the matrix, part of the residual stress is released and hence the residual stress decreases. Considering similar thermal changes, the amount of this stress is dependent on the fiber volume ratio. These stresses play a role in lateral and shear damage. Hook et al. (2008), assessed the effect of geometry in effective material properties and stress distribution considering various finite element models.

Shokrieh and Ghanei (2010) considered a single fiber circular composite to assess residual thermal stresses in a finite element simulation. The interphase properties were considered to vary cubic, exponentially and periodically, radially and found that the results coincide with proper boundary conditions and neglecting the interphase causes obvious errors. Shokrieh and Safarabadi (2011), utilizing the Energy method and considering average interphase properties found the micromechanical residual stress in various points of the RVE. They evaluated the effect of the modulus of elasticity, Poisson's ration and the thermal expansion coefficient of the interphase on micromechanical residual stresses. They used ABAQUS CAE considering seven layers for the interphase to compare the results. Shokrieh and Safarabadi (2012a) have reported that axial and sheer stresses increase not only because of an increase in the fiber length, but also due to the order of mismatch in thermal and mechanical properties and high mismatch in coefficient of the thermal expansion and Young's modulus. By comparing the theoretical and numerical results together, inability of finite element in elucidation boundary conditions at the composition ends resolved.

Shokrieh et al. (2012) reported finite-element analysis as a new three-dimensional analytical model, based on the energy method, is developed to present residual stresses, which is a little higher in representative volume element (RVE) in polymer composites. Because of not considering the edge singularity in this method, a maximum shear stress is reached at composite ends in comparison at vicinity of fiber ends. In this study, first, the interphase properties' equations is found using previous studies; then a finite element solution is used and micromechanical residual stress curves are plotted 
and the results are compared with previous research. Finally, the effect of the mechanical and thermal properties' bonding efficiencies are evaluated.

\section{Micromechanical residual stress distribution prediction using the finite element solution}

In this part, first, the interphase equations are found using previous studies. Then the finite element solution is described. In the finite element solution an appropriate UMAT program is used.

\section{2-1. Interphase property prediction}

Initially the interphase properties, which depend on the matrix and fiber properties, need to be found. Papanicolaou et al. (2002) presented a precise two dimensional model to determine the micromechanical properties of the interphase under thermal load.

$$
P_{j}=\left\{\begin{array}{llr}
1+\left(\lambda_{j} q_{j}-1\right) R_{j}(\rho) & \text { if } & 1 \leq \rho<\rho_{h j} \\
1 & \text { if } & \rho=\rho_{i j}
\end{array}\right.
$$

in which $P_{j}$ can be the modulus of elasticity, Poison's ratio and thermal expansion coefficient (Eq 2). $q_{j}$ Which is the property mismatch index is found from equation 3. $\lambda_{j}$ And $\rho$ are the mechanical and thermal bonding property efficiencies at $\mathrm{r}=R_{f}$ and the normal radial distance with respect to the fiber radius respectively. $R_{j}(\rho)$ Accounts for the geometry and bonding efficiency aspects of the model, which is found from $\mathrm{Eq}(4)$.

$$
\begin{aligned}
& P_{j}(\rho)= \begin{cases}\frac{E_{i}}{E_{m}} & j=1 \\
\frac{\mathrm{v}_{i}}{\mathrm{v}_{m}} & j=2 \\
\frac{\alpha_{i}}{\alpha_{m}} & j=3\end{cases} \\
& q_{j}= \begin{cases}\frac{E_{f}}{E_{m}} & j=1 \\
\frac{\mathrm{v}_{f}}{\mathrm{v}_{m}} & j=2 \\
\frac{\alpha_{f}}{\alpha_{m}} & j=3\end{cases} \\
& R_{j}(\rho)=\frac{1-\left(\rho / \rho_{j}\right) \operatorname{EXP}\left[1-\lambda_{j}(\rho-1) /\left(1-\lambda_{j}\right) S_{j}\right]}{\left(1-1 / \rho_{j}\right) \operatorname{EXP}\left[1-\lambda_{j}\left(\rho_{j}-1\right) /\left(1-\lambda_{j}\right) S_{j}\right]},
\end{aligned}
$$

where Eq. (4) $\rho_{j}$ and $S_{j}$ are interphase to fiber radius ratio and anisotropy index respectively.

$$
S_{j}= \begin{cases}\frac{E_{T}}{E_{L}} & j=1 \\ \frac{\mathrm{v}_{T}}{\mathrm{v}_{L}} & j=2 \\ \frac{\alpha_{T}}{\alpha_{L}} & j=3\end{cases}
$$

In Eq. (5), $\mathrm{t}$ and 1 are principal values of material properties along transverse and longitude directions respectively.

\subsection{Residual stress prediction}

In Fig. 1, the considered RVE for the finite element solution is seen. This RVE is in all three phases. 


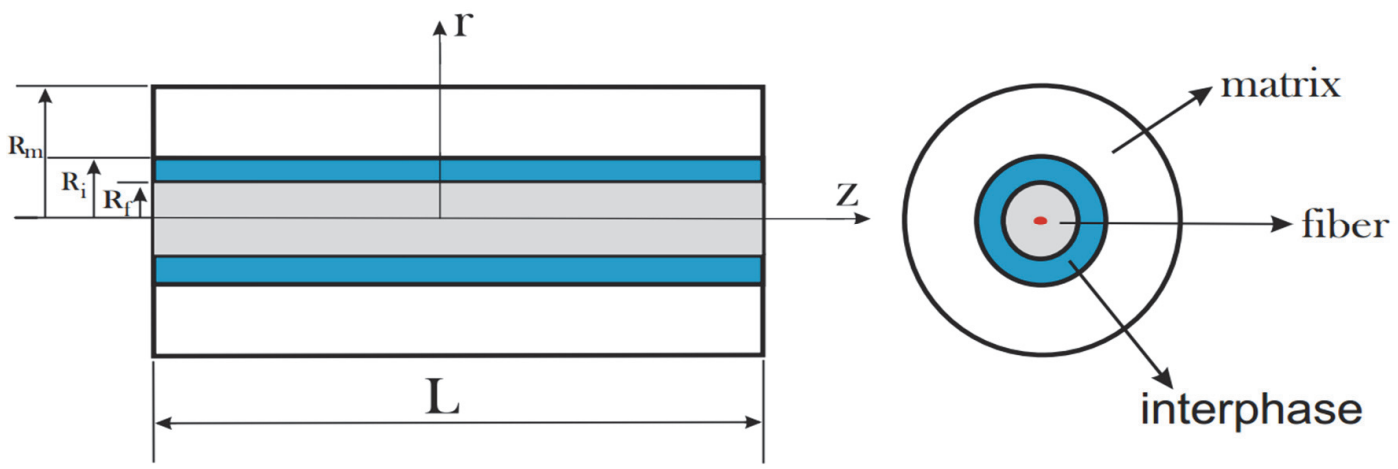

Fig. 1. RVE considered for predicting micromechanical stresses

The considered composite in this study is glass-epoxy, whose properties have been presented in Table 1.

Table 1. Glass epoxy composite properties (Shokrieh \& Safarabadi, 2012b)

\begin{tabular}{lccc}
\hline & Fiber & Matrix & Interphase \\
\hline Young's modulus $(G P d)$ & 77 & 3.1 & 10.2 \\
Poisson's ratio & 0.2 & 0.34 & 0.25 \\
Coefficient of thermal expansion $\left(10^{-6} /{ }^{\circ} \mathrm{C}\right)$ & 5.4 & 70 & 20 \\
Radius $(\mu m)$ & 6 & 8.5 & $6.3,6.4,6.7$ \\
\hline
\end{tabular}

In order to development a numerical model, the finite element model is also assessed. Due to the geometric symmetry and boundary conditions a quarter of the RVE is modeled and symmetry constraints are used. The finite element model and its features are shown in Fig. 2 and Table 1 respectively. C3D8R elements were used for meshing the finite element model. In the axial direction half of the RVE is modelled and one end of the model (which represents the middle of the RVE) is constrained.

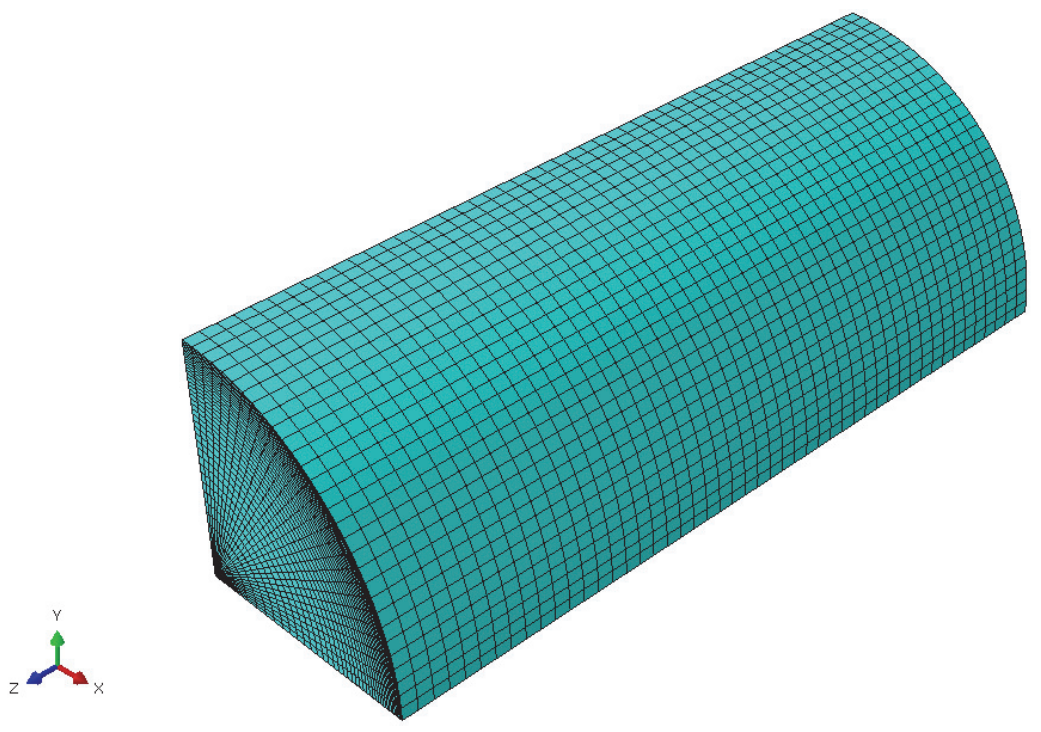

Fig. 2. Finite element model 
Table 1. Finite element model parameters

\begin{tabular}{lll}
\hline Element & Type & number \\
\hline Linear hexahedral & C3D8R & $\mathbf{5 7 3 3 0}$ \\
Linear wedge & C3D6 & $\mathbf{1 4 7 0}$ \\
& Number of nodes:62050 \\
& Number of elements:58800 & \\
\hline
\end{tabular}

In the finite element model, the interphase properties have been considered to be varying using Eq. 1. To this extent a UMAT program is used to consider varying properties in the radial direction. In this solution only an 80 degree load is present and there is no constraint.

\section{Results and Discussions}

The interphase thickness has been found to be $0.3,0.4$ and 0.7 micrometers (Shokrieh \& Safarabadi 2011). In this section, first the micromechanical residual stress curves found using the ABAQUS software for a glass-epoxy composite for different thicknesses are assessed and are compared with previous studies. The interphase stress curves are also evaluated. Then the thermal expansion bonding efficiency is discussed.

\subsection{Stress distribution in fiber and resin}

In Fig. 3a, the axial stress distribution in the matrix is shown. As is seen, increasing the interphase thickness leads to lower stresses. Also, the results found from the finite element solution are higher than the energy method (Shokrieh \& Safarabadi, 2011) considering average properties, but are close. The maximum stress is in the middle of the RVE, and at the ends the axial stress is zero. Fig. 3b, shows axial stress distribution in the fiber. Increasing the interphase thickness decreases the amount of stress. In this section the results are close and the maximum stress is in the middle of the RVE; the stresses at the ends of the element are zero.

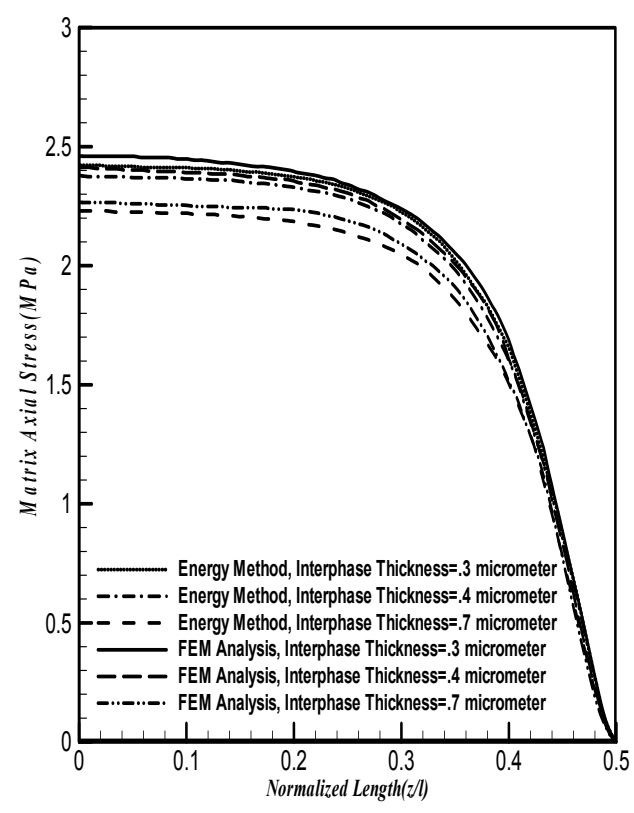

(a)

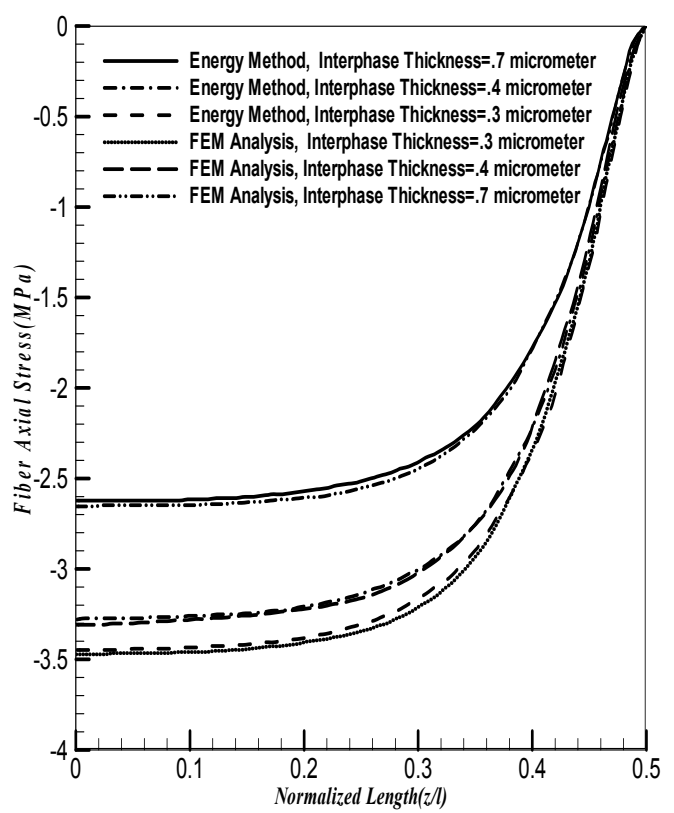

(b)

Fig. 3. axial stress distribution using the finite element solution (considering variable properties) and the energy method (Shokrieh and Safarabadi, 2011) for different interphase thicknesses for the matrix (a) and the fiber (b) 
Fig. 4 shows surface shear stress between the fiber and interphase. The stresses from the finite element solution are lower than the energy method (Shokrieh \& Safarabadi, 2011). Also the stress in the finite element solution tends to zero at free surfaces but is not zero which is in contradiction with the stress free ends assumption (but the energy method (Shokrieh \& Safarabadi, 2011)is in accordance with the assumption). Fig. $4 \mathrm{~b}$ shows fiber and interphase surface radial stress. The finite element solution and energy method results (Shokrieh \& Safarabadi, 2011) are in accordance with each other. The stress curves for both methods tends to zero at the RVE ends which are due to the edge effect.

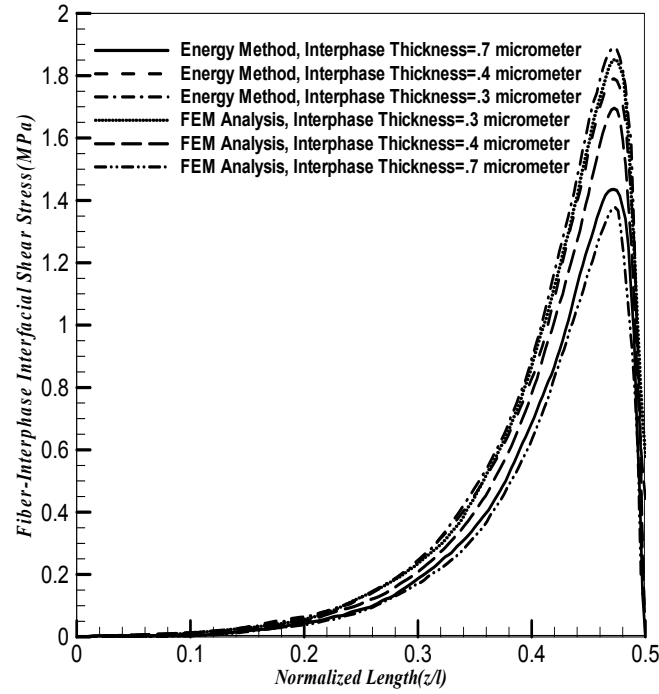

Fig. 4. Fiber-interphase surface shear stress distribution using finite element simulation considering variable interphase properties for different interphase thicknesses

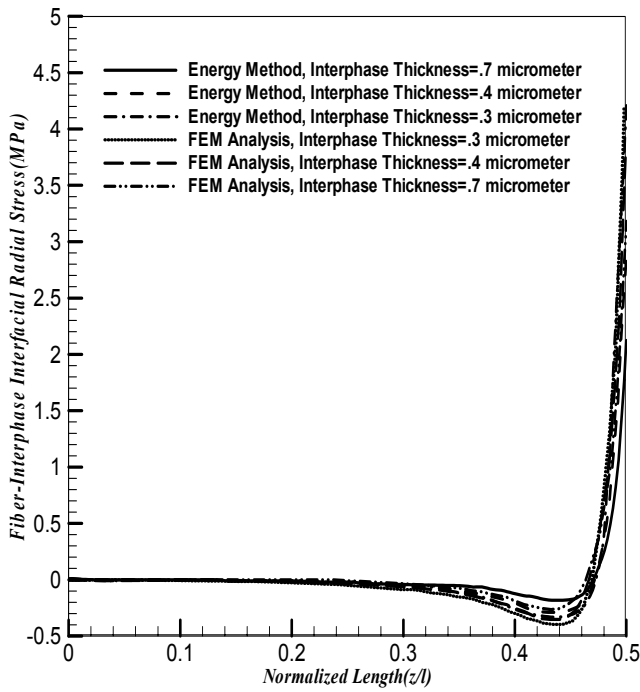

Fig. 5. Fiber interphase surface radial stress distribution using finite element simulation considering variable interphase properties for different interphase thicknesses

\subsection{Interphase stress distribution}

In this section the interphase axial and shear stress distribution curve, along the radius, in the element middle and quarter length is discussed (Fig. 1).

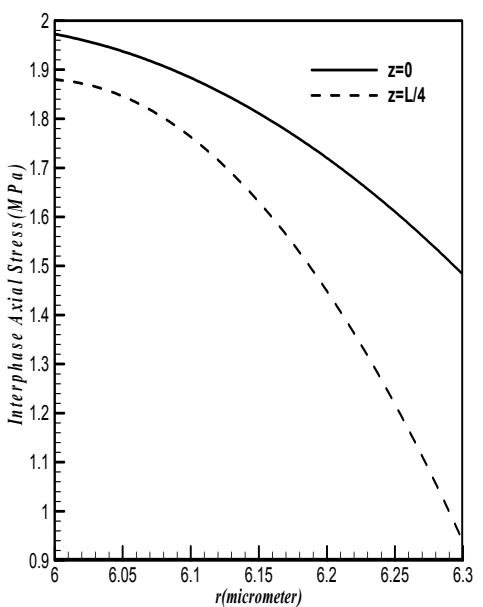

(a)

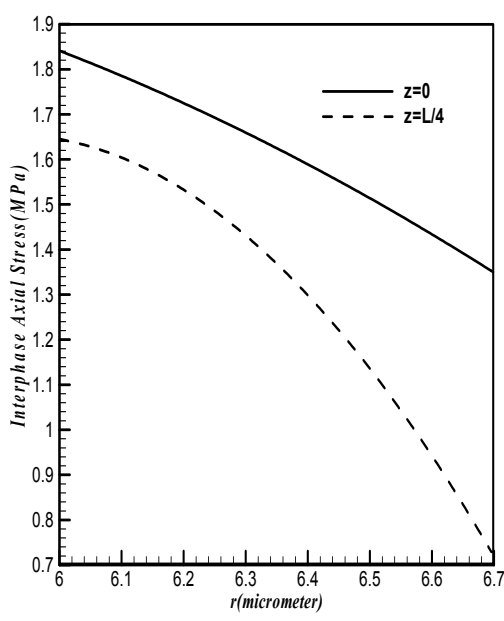

(b)

Fig. 6. Interphase axial stress distribution along the radius for interphase thicknesses of 0.3 micrometers (a) and 0.7 micrometers (b) 
Fig 6. ( $\mathrm{a}$ and $\mathrm{b}$ ) shows the interphase axial stress distribution curve along the radius for 0.3 micrometer and 0.7 micrometer interphase thicknesses respectively. As is seen, as the interphase radius increases (from the fiber to the matrix), the interphase axial stress decreases. Moving towards the element end, the stress decreases. Comparing Fig. 6 (a) and (b) we can see that as the interphase thickness decreases, the axial stresses increase.

Fig. 7 (a) and (b) shows interphase shear stress curve along the radius for interphase thickness of 0.3 and 0.7 micrometers respectively. The amounts of these stresses are close to zero and as the interphase thickness increases (from fiber to matrix), the interphase shear stress tends to zero. Also moving towards the element end, the stress decreases.

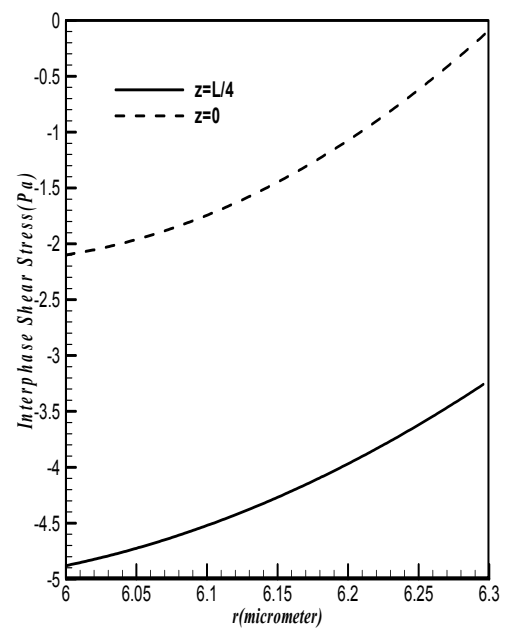

(a)

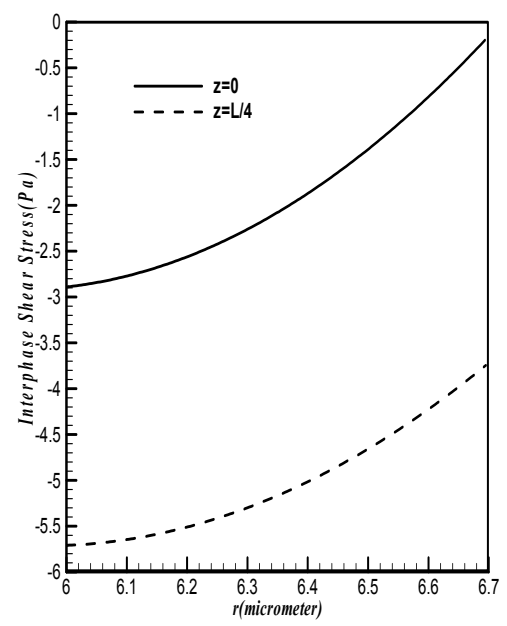

(b)

Fig. 7. Interphase shear stress distribution along the radius for interphase thickness of (a) 0.3 micrometers and (b) 0.7 micrometers

\subsection{Thermal expansion coefficient bonding efficiency effect}

In this section the effect of the thermal expansion coefficient bonding efficiency, which is the most important factor, is assessed.

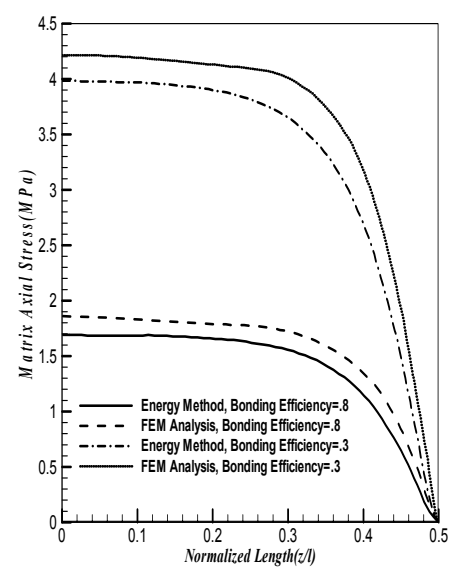

(a)

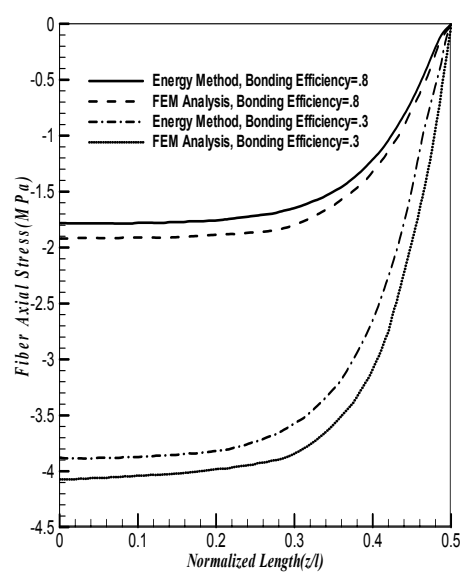

(b)

Fig. 8. Axial stress distribution from the finite element solution for variable interphase properties and different bonding efficiencies for the matrix (a) and fiber (b) 
Fig. 8 ( $\mathrm{a}$ and $\mathrm{b}$ ) shows the axial stress in the matrix and fiber respectively for two thermal expansion coefficient bonding efficiencies of 0.3 and 0.8 . The stresses from the finite element solution are higher and increasing the bonding efficiency decreases stress.

In Fig. 9 and Fig. 10, the radial stress distribution curve between the fiber and interphase for two bonding efficiencies of 0.3 and 0.8 is seen. The shear stress curves obtained from the finite element solution do not reach zero and these stresses are lower than those obtained from the energy method (Shokrieh \& Safarabadi, 2011). Increasing the bonding efficiency, decreases stress. By increasing the bonding efficiency in the shear stress curve and moving towards the end of element, initially the stresses increase and then decrease.

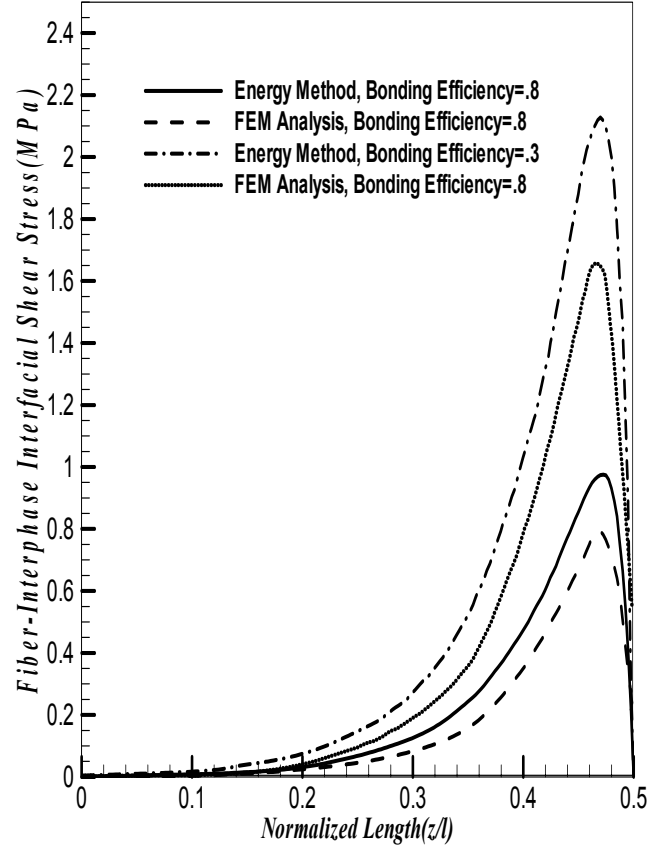

Fig. 9. Fiber-interphase surface shear stress distribution using the finite element solution considering variable interphase properties and different bonding efficiencies

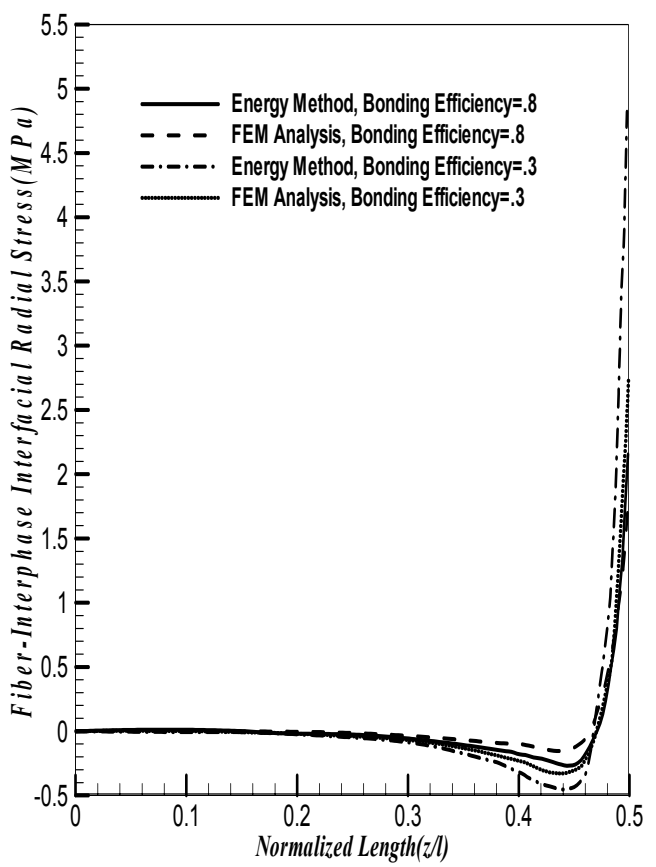

Fig. 10. fiber interphase surface radial stress distribution using the finite element solution for variable interphase properties and different bonding efficiencies

\section{Conclusions}

Considering the interphase is of importance in finding more precise stresses in composites. In this study, the interphase properties have been considered to be variable (using the ABAQUS software), in order to yield precise micromechanical residual stresses. Incorporating the micro residual stresses found, with macro residual stresses can yield to more precise residual stress estimation in composites. The axial and shear stress distribution curves in the interphase have been presented for the first time. The following results have been obtained in this study:

- Increasing the interphase thickness decreases stress in the matrix and fiber

- The matrix axial and shear stresses from the finite element solution considering variable properties are higher than the energy method considering average properties

- As the interphase radius increases (from the fiber to the matrix), the interphase axial stress decreases 
V. Teimouri and M. Safarabadi / Engineering Solid Mechanics 6 (2018)

- As we move towards the end of the element, the interphase axial stress decreases

- Decreasing interphase thickness, increases interphase axial stress

- Increasing the thermal expansion bonding efficiency, decreases matrix and fiber axial stresses

Overall, the results from the finite element solution considering variable properties, show little difference to those of the energy method considering average properties. The shear stresses in the interphase, in the element middle and at quarter length, are approximately zero. Using the micro residual stresses obtained here with the macro residual stresses obtained in previous studies may lead to more precise residual stress estimation.

\section{References}

Aghdam, M. M., \& Khojeh, A. (2003). More on the effects of thermal residual and hydrostatic stresses on yielding behavior of unidirectional composites. Composite Structures, 62(3), 285-290.

Chen, Y., Xia, Z., \& Ellyin, F. (2001). Evolution of residual stresses induced during curing processing using a viscoelastic micromechanical model. Journal of Composite Materials, 35(6), 522-542.

Ghasemi, A. R. \& Shokrieh M. M. (2008). Development of an integral method for determination of non-uniform residual stresses in laminated composites. Journal of Composite Materials, 21(4), 347355.

Hobbiebrunken, T., Fiedler, B., Hojo, M., Ochiai, S., \& Schulte, K. (2005). Microscopic yielding of $\mathrm{CF} /$ epoxy composites and the effect on the formation of thermal residual stresses. Composites Science and Technology, 65(10), 1626-1635.

Jin, K. K., Huang, Y., Lee, Y. H., \& Ha, S. K. (2008). Distribution of micro stresses and interfacial tractions in unidirectional composites. Journal of Composite Materials, 42(18), 1825-1849.

Karami, G., \& Garnich, M. (2005). Micromechanical study of thermoelastic behavior of composites with periodic fiber waviness. Composites Part B: Engineering, 36(3), 241-248.

Papanicolaou, G. C., Michalopoulou, M. V., \& Anifantis, N. K. (2002). Thermal stresses in fibrous composites incorporating hybrid interphase regions. Composites Science and Technology, 62(14), 1881-1894.

Shokrieh, M. M., \& Mohammadi, A. G. (2010, January). Investigation of Residual Thermal Stresses in Fiber-Reinforced Composites Incorporating Inhomogeneous Interphase Region. In ASME 2010 International Mechanical Engineering Congress and Exposition (pp. 645-654). American Society of Mechanical Engineers.

Shokrieh, M. M., \& Safarabadi, M. (2011). Effects of imperfect adhesion on thermal micro-residual stresses in polymer matrix composites. International Journal of Adhesion and Adhesives, 31(6), 490-497.

Shokrieh, M. M., \& Safarabadi, M. (2012a). Influence of Physical, Thermal and Mechanical Parameters on Micro Residual Stresses in Polymeric Composites. Iranian Journal of Polymer Science and Technology, 24(5), 355-368.

Shokrieh, M. M., \& Safarabadi, M. (2012b). Three-dimensional analysis of micro residual stresses in fibrous composites based on the energy method: a study including interphase effects. Journal of Composite Materials, 46(6), 727-735.

Shokrieh, M. M., Safarabadi, M., \& Ghaanee, A. R. (2012). A new three-dimensional analytical model to simulate microresidual stresses in polymer matrix composites. Mechanics of Composite Materials, 48(3), 273-284.

Tay, T. E., \& Shen, F. (2002). Analysis of delamination growth in laminated composites with consideration for residual thermal stress effects. Journal of Composite Materials, 36(11), 12991320.

Zhang, Y., Xia, Z., \& Ellyin, F. (2004). Evolution and influence of residual stresses/strains of fiber reinforced laminates. Composites Science and Technology, 64(10), 1613-1621. 
(C) 2018 by the authors; licensee Growing Science, Canada. This is an open access article distributed under the terms and conditions of the Creative Commons Attribution (CC-BY) license (http://creativecommons.org/licenses/by/4.0/). 